\title{
Efficacy and Safety of Topical 2\% Glycopyrrolate in the Treatment of Facial Hyperhidrosis
}

\author{
Eman Abd Elgawad Nofal, Shrook Abd Elshafy Khashaba, Somya Salem Elsayed Hasan* \\ Dermatology, Venereology and Andrology Department, Faculty of Medicine, Zagazig University, Egypt. \\ *Corresponding author: Somya Salem Elsayed Hasan, Mobile: (+20)01119680224, E-mail: salemsomya@ gmail.com
}

\begin{abstract}
Background: Facial hyperhidrosis is a frequent complaint characterized by excessive sweating which usually affects the forehead bilaterally but can also involve other regions of the face such as the scalp, nose, chin and less frequently cheeks. The topical application of $2 \%$ glycopyrrolate is safe, efficacious, well tolerated and convenient method in the treatment of facial hyperhidrosis. Objective: The aim of this study was to evaluate the clinical efficacy, safety and tolerability of topical $2 \%$ glycopyrrolate in the treatment of facial hyperhidrosis.

Patients Methods: This clinical trial was conducted in the Outpatient Clinics of Dermatology, Venereology and Andrology Department, Faculty of Medicine, Zagazig University Hospitals. Twelve patients suffering from primary facial hyperhidrosis were included in this study. They were treated by topical glycopyrrolate gel $2 \%$. Each patient applied the test product to the area affected in their faces once a day for 9 days. Response to treatment was evaluated by starch iodine test. Patient's satisfaction level and adverse effects were also evaluated. Follow up evaluation was done for detection of any recurrence.

Results: 9 patients (75\%) showed complete response and 2 patients (16.7\%) showed partial response. Only one patient showed no response to topical glycopyrrolate $2 \%$ after 10 days of treatment. The improvement was lost in 8 patients $(66.7 \%)$ on the 3rd day of stoppage of treatment and on the next day of stoppage of treatment among 3 patients $(25 \%)$.

Conclusion: Topical glycopyrrolate $2 \%$ is safe, efficacious, well tolerated and convenient method in the treatment of facial hyperhidrosis with minimal, transient and well-tolerated side effects.

Keywords: Glycopyrrolate, Facial hyperhidrosis.
\end{abstract}

\section{INTRODUCTION}

Hyperhidrosis is a disorder characterized by excessive sweating. It is a common health problem affecting about $3 \%$ of the population. Patients with hyperhidrosis usually have low self-esteem and frequently withdraw from the social arena. They can have secondary effects such as damp, cold hands, dehydration and skin infections secondary to maceration. Hyperhidrosis is classified according to cause into primary or secondary and can be categorized based on the source of the neural impulses that drive it into cortical (emotional), hypothalamic, medullary, spinal cord and local axon reflex ${ }^{(\mathbf{1})}$.

Facial hyperhidrosis is a frequent complaint, which usually affects the forehead bilaterally but can also involve other regions of the face such as the scalp, nose, chin and less frequently cheeks. It can be either focal affecting only the face and scalp or part of a generalized hyperhidrosis involving several body sites of skin. It could be primary or secondary to other causes such as infection, endocrine disturbance or neoplasm (2). Primary facial hyperhidrosis is characterized by sudomotor dysregulation stimulated by triggers such as heat and stress. The possibility exists that the cause of primary facial hyperhidrosis could be excessive stimulation of the sweat glands by an overactive sympathetic system or by overreaction of the glands to a normal amount of acetylcholine ${ }^{(3)}$.

There are many available treatments for facial hyperhidrosis including systemic treatment as anticholinergic drugs but unfortunately, high doses are often required with possible side effects such as insomnia, altered mental status, seizures, palpitation and urine retention. Topical antiperspirants as topical $20 \%$ aluminum chloride could be attempted in the treatment of facial hyperhidrosis with possible local irritation and contact dermatitis. Surgical management can be used for the treatment of facial hyperhidrosis. The principle behind it is disruption of nerve impulses from sympathetic nervous ganglia (predominantly T2T3) to the eccrine sweat glands ${ }^{(4)}$.

Glycopyrrolate is an anticholinergic agent that blocks acetylcholine receptors lowering gastric, bronchial, lacrimal and other body secretions. The topical application of $2 \%$ glycopyrrolate appears to be safe, efficacious, well tolerated and convenient in the treatment of facial hyperhidrosis with few secondary effects such as slight headache, dry mouth or odynophagia $^{(5)}$.

\section{PATIENTS AND METHODS}

This clinical trial was conducted in the Outpatient Clinics of Dermatology, Venereology and Andrology Department, Faculty of Medicine, Zagazig University Hospitals during the period from June 2020 to February 2021.

Twelve patients suffering from primary facial hyperhidrosis were included in this study. They were treated by topical glycopyrrolate gel $2 \%$. 
Ethical consent:

An approval of the study , Zagazig University Academ Committee. Every patient sig written consent for acceptance work has been carried out in ar Code of Ethics of the World N (Declaration of Helsinki) for humans.

Inclusion criteria: Patients suff facial hyperhidrosis to the degree their daily activities, sex both mi range from 15 to 70 years old, enrolled for the complete study per Exclusion criteria: Patients hyperhidrosis, patients with prior anticholinergics or glycopyrrolate lactation.

All patients were subjected to the - Complete history taking: F name, sex, age, occupation, reside past history of previous treatment and family history of hyperhidrosis.

- Complete general examination: To exclude secondary cause of hyperhidrosis as diabetes mellitus, infection and thyrotoxicosis.

- Complete dermatological examination: To detect the sites of hyperhidrosis and hyperhidrosis by minor starch iodi1

Pre-procedure consultation: The course of treatment and potential $\mathrm{s}$ explained to all patients. Patients Glycopyrrolate $2 \%$ gel. All patients । wash his or her face with soap a application to ensure optimal absor! also given a complete demonstration the test product, and the possible co explained. Patients were warned tc their eyes, noses and mouths befo: hands after application of the test proc applied the test product to the area faces once a day for 9 days.

\section{Patients' assessment:}

A. Clinical assessment: All patients minor starch iodine test before and : assess the response. Sweat reduction $1^{\text {st }}$ and $10^{\text {th }}$ day of application of trea $\& b$ and Figure 2a $\&$ b).

\section{B. Assessment of response:}

The response was assessed using the $\mathrm{f}$

- Complete response: more than 7 sweating.

- Partial response: between $35 \%$ tó sweating.

- No response: Less than 35\% reduction of sweating (6)

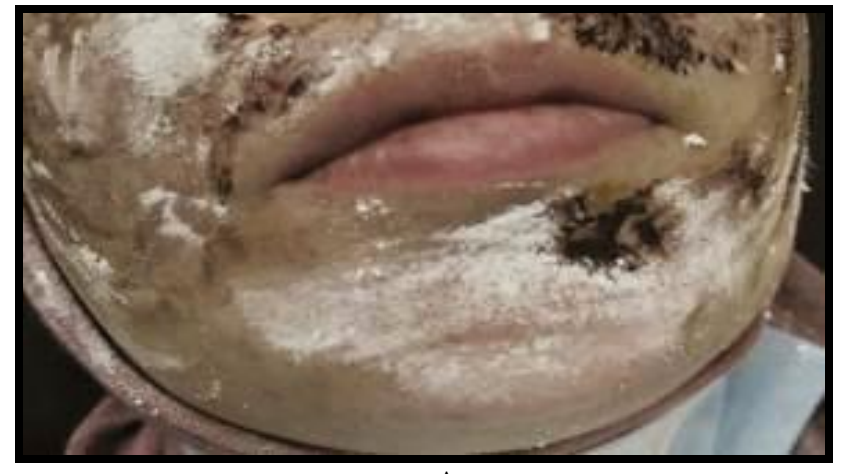

A

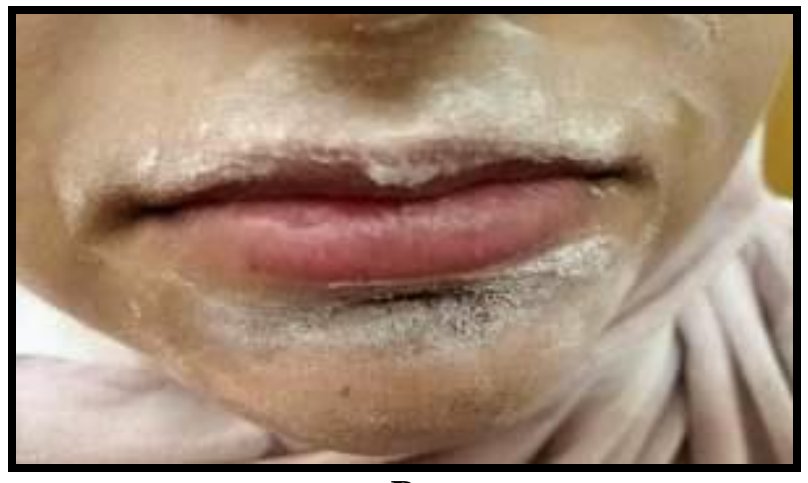

B

Figure (1): (A) Female patient19 years old with positive starch iodine test before treatment. (B) Same patient 10 days after topical glycopyrrolate $2 \%$ application around the mouth showing complete response (90\% reduction of sweating).

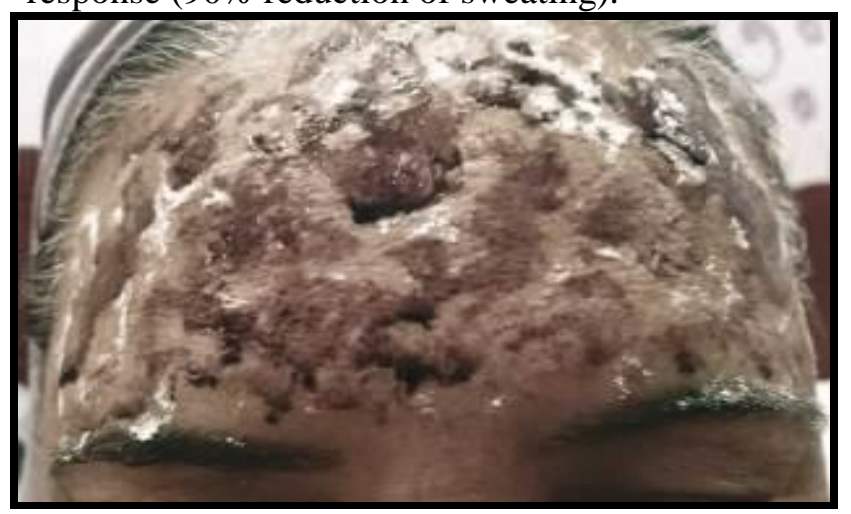

A

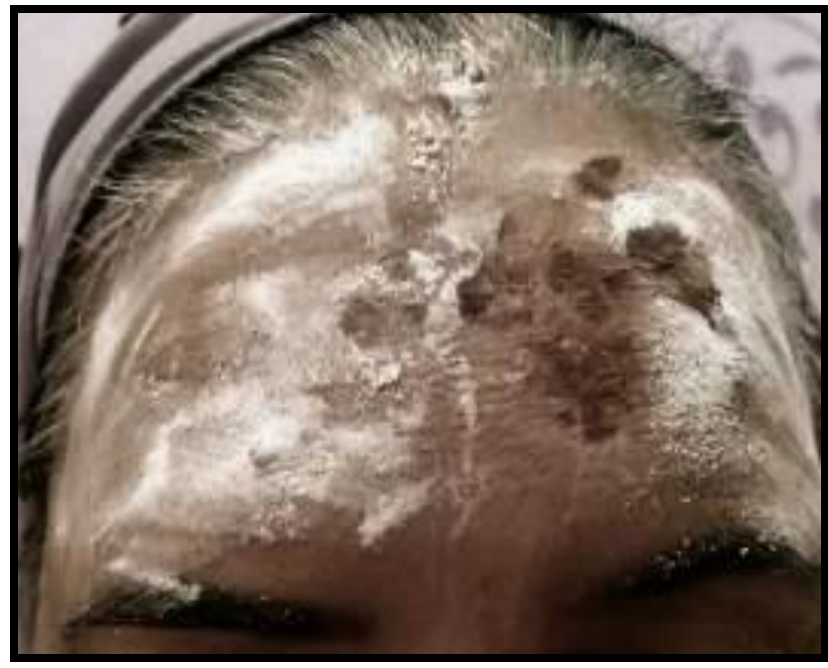

B

Figure (2): (A) Female patient 53 years old with positive starch iodine test before treatment. (B) Same patient 10 days after topical glycopyrrolate 2\% 
application in the forehead showing complete response (80\% reduction of sweating).

\section{Hyperhidrosis Disease severity scale (HDSS):}

The scale is based on the question: 'How would you rate the severity of your hyperhidrosis?'

- My sweating is never noticeable and never interferes with daily activities.

- My sweating is tolerable but sometimes interferes with daily activities.

- My sweating is barely tolerable and frequently interferes with daily activities.

- My sweating is intolerable and always interferes with daily activities ${ }^{(3)}$.

\section{Dermatology Life Quality Index (DLQI):}

Dermatology Life Quality Index (DLQI) depicts different domains of QOL using 10 questions with maximum score of 30. Each question is scored 0-3 and total score before treatment and at the follow up visits is obtained. The results of the questionnaire could then be easily translated into the effect of the skin condition on QOL using a banding system (0-1 no effect, 2-5 small effect, 6-10 moderate effect, 11-20 very large effect and 21-30 extremely large effect) ${ }^{(7)}$.

\section{E. Patients' satisfaction:}

All patients were asked to grade the overall percentage of satisfaction with treatment as very satisfied (5), somewhat satisfied (4), neither satisfied nor dissatisfied (3) somewhat dissatisfied (2) or very dissatisfied (1).

\section{F. Safety and side effects evaluation:}

Patients were monitored for any complications and side effects during and after treatment.

\section{Statistical analysis}

The collected data were coded, processed and analyzed using the SPSS (Statistical Package for Social Sciences) version 22 for Windows ${ }^{\circledR}$ (IBM SPSS Inc, Chicago, IL, USA). Data were tested for normal distribution using the Shapiro Walk test. Qualitative data were represented as frequencies and relative percentages. Chi square test $\left(\chi^{2}\right)$ to calculate difference between two or more groups of qualitative variables. Quantitative data were expressed as mean \pm SD (Standard deviation). Independent samples t-test was used to compare between two independent groups of normally distributed variables (parametric data). $\mathrm{P}$ value $\leq 0.05$ was considered significant.

\section{RESULTS}

This study included 12 patients with primary facial hyperhidrosis. All of them completed the study and no one was excluded in the analysis. All patients were females. Their ages ranged from 18-53 with a mean of $32.92 \pm 14.09$ years. Three patients $(25 \%)$ had positive family history of hyperhidrosis. Duration of facial hyperhidrosis among them ranged from 1-5 years with mean $2.33 \pm 1.44$ years (Table 1 ).

The forehead was the only site affected in 7 patients $(58.3 \%)$, while the whole face was affected in 3 patients $(25 \%)$. Only one patient had hyperhidrosis in the upper lip and chin only and the last one had hyperhidrosis in the whole face except the forehead. Four patients had hyperhidrosis in the axilla and 1 patient in the palms and soles. Nine patients (75\%) showed complete response and 2 patients (16.7\%) showed partial response. Only one patient showed no response to topical glycopyrrolate $2 \%$ after 10 days of treatment. The effect started on the same day of the application of glycopyrrolate $2 \%$ among 7 patients $(50.0 \%)$ and on the next day in 5 patients $(41.7 \%)$. The improvement was lost in 8 patients $(66.7 \%)$ on the 3 rd day of stoppage of treatment and on the next day of stoppage of treatment among 3 patients $(25 \%)$.

The mean of HDSS before topical glycopyrrolate $2 \%$ was $3.08 \pm 0.67$ with range of 2-4 that became 1.67 \pm 1.07 with range of $1-4$ after 10 days of treatment. The mean of DLQI decreased from $9.83 \pm 0.83$ before the treatment to $3.33 \pm 2.83$ after the treatment. The difference was statistically significant. 8 patients $(66.7 \%)$ were somewhat satisfied with treatment, while 2 patients $(16.7 \%)$ were very satisfied. On the other hand, one patient was neither satisfied nor dissatisfied and one patient was very dissatisfied (Table 2).

Regarding side effects of topical glycopyrrolate $2 \%$, one patient reported compensatory hyperhidrosis in the axilla, one patient had mild skin irritation and itching that resides in the $2^{\text {nd }}$ day of application and one patient complained from mild headache in the first 2 days of application. No one reported anticholinergic side effects as dry mouth, tachycardia, urine retention or constipation. 
Table (1): Demographic and clinical data of the studied groups

\begin{tabular}{|c|c|c|c|c|c|c|}
\hline \multirow[b]{2}{*}{ Variables } & \multicolumn{4}{|c|}{ Studied groups } & \multirow[b]{2}{*}{ Test of sig } & \multirow[b]{2}{*}{ p-value } \\
\hline & \multicolumn{2}{|c|}{\begin{tabular}{|} 
Group A (Intradermal \\
Botulinum Toxin) \\
Mean \pm SD \\
N $(\%)$
\end{tabular}} & \multicolumn{2}{|c|}{\begin{tabular}{|c|} 
Group B \\
(Topical \\
Glycopyrrolate 2\%) \\
Mean \pm SD \\
N $(\%)$ \\
\end{tabular}} & & \\
\hline $\begin{array}{l}\text { Age in years } \\
\text { Mean } \pm \text { SD } \\
\text { Median (Range) }\end{array}$ & \multicolumn{2}{|c|}{$\begin{array}{r}31.58 \pm 9.2 \\
29(19-55)\end{array}$} & \multicolumn{2}{|c|}{$\begin{array}{c}32.92 \pm 14.09 \\
32(18-53)\end{array}$} & $\mathrm{U}=0.84$ & $\begin{array}{l}0.202 \\
(\mathrm{NS})\end{array}$ \\
\hline $\begin{array}{l}\text { Sex } \\
\text { Males } \\
\text { Females } \\
\end{array}$ & $\begin{array}{l}4 \\
8 \\
\end{array}$ & $\begin{array}{l}33.3 \\
66.7\end{array}$ & $\begin{array}{c}0 \\
12 \\
\end{array}$ & $\begin{array}{c}0 \\
100 \\
\end{array}$ & $\mathrm{f}$ & $\begin{array}{c}0.093 \\
(\mathrm{NS})\end{array}$ \\
\hline $\begin{array}{l}\text { Family history } \\
\text { Negative } \\
\text { Positive }\end{array}$ & $\begin{array}{l}6 \\
6 \\
\end{array}$ & $\begin{array}{l}50.0 \\
50.0\end{array}$ & $\begin{array}{l}9 \\
3\end{array}$ & $\begin{array}{l}75.0 \\
25.0\end{array}$ & $\mathrm{f}$ & $\begin{array}{c}0.4 \\
(\mathrm{NS})\end{array}$ \\
\hline $\begin{array}{l}\text { Disease duration in years } \\
\text { Mean } \pm \text { SD }\end{array}$ & \multicolumn{2}{|c|}{$3.25 \pm 1.82$} & \multicolumn{2}{|c|}{$2.33 \pm 1.44$} & $\mathrm{U}=1.29$ & $\begin{array}{l}0.22 \\
(\mathrm{NS})\end{array}$ \\
\hline $\begin{array}{l}\text { Site of facial } \\
\text { hyperhidrosis }\end{array}$ & 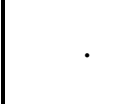 & 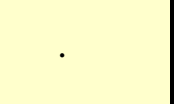 & . & & & \\
\hline Forehead only & 8 & 66.6 & 7 & 58.3 & & \\
\hline Upper lip and chin only & 3 & 25 & 1 & 8.3 & $\chi^{2}=1.58$ & 0.66 \\
\hline $\begin{array}{l}\text { Whole face except } \\
\text { forehead }\end{array}$ & 0 & 0 & 1 & 8.3 & & (NS) \\
\hline Whole face & 1 & 8.3 & 3 & 25.0 & & \\
\hline $\begin{array}{l}\text { Presence of other sites of } \\
\text { hyperhidrosis }\end{array}$ & 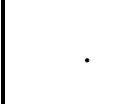 & $\cdot$ & - & & & \\
\hline No & 6 & 50 & 7 & 58.3 & & \\
\hline Palm and sole & 2 & 16.7 & 1 & 8.3 & $\chi^{2}=1.67$ & 0.54 \\
\hline Axilla & 4 & 33.3 & 4 & 33.3 & & (NS) \\
\hline
\end{tabular}

Continuous data presented as Mean \pm SD, Median (Range). Categorical data as number (\%)

$\chi^{2}$ Chi square test $\quad U=$ Mann-Whitney $U$ test $f=$ Fisher's Exact Test $p>0.05$ nonsignificant

Table (2): Comparison of Hyperhidrosis Disease Severity Scale and Daily Life Quality Index before and after treatment with topical glycopyrrolate $2 \%$

\begin{tabular}{|c|c|c|c|c|}
\hline & \multicolumn{2}{|c|}{$\begin{array}{c}\text { Group B (Topical } \\
\text { Glycopyrrolate 2\%) }\end{array}$} & \multirow[b]{2}{*}{$\mathbf{w}$} & \multirow[b]{2}{*}{ p-value } \\
\hline & $\begin{array}{c}\text { Before } \\
\text { treatment }\end{array}$ & $\begin{array}{c}\text { After } \\
\text { treatment }\end{array}$ & & \\
\hline $\begin{array}{l}\text { Hyperhidrosis Disease Severity Scale (HDSS) } \\
\text { Mean } \pm \text { SD } \\
\text { Median (range) }\end{array}$ & $\begin{array}{c}3.08 \pm 0.67 \\
3(2-4)\end{array}$ & $\begin{array}{c}1.67 \pm 1.07 \\
1(1-4)\end{array}$ & 3.02 & 0.003 \\
\hline $\begin{array}{l}\text { Daily Life Quality Index (DLQI) } \\
\text { Mean } \pm \text { SD } \\
\text { Median (range) }\end{array}$ & $\begin{array}{c}9.83 \pm 0.83 \\
10(9-11)\end{array}$ & $\begin{array}{c}3.33 \pm 2.83 \\
2(1-10)\end{array}$ & 2.96 & 0.003 \\
\hline
\end{tabular}




\section{DISCUSSION}

In the present study, 9 patients $(75 \%)$ showed complete response, 2 patients $(16.7 \%)$ showed partial response and only one patient showed no response after 10 days of treatment. The effect started on the same day of the application among 7 patients (50.0\%) and on the next day in 5 patients $(41.7 \%)$.

The effect of topical glycopyrrolate $2 \%$ was lost on the next day of stoppage of treatment among 3 patients (25\%), on the 3rd day of stoppage of treatment in 8 patients $(66.7 \%)$. Similarly, Kim et al. ${ }^{(3)}$ reported that the period before recurrence of sweating after topical glycopyrrolate $2 \%$ was $<1$ day in seven patients $(28 \%)$. Seventeen patients $(68 \%)$ experienced light sweating on their foreheads on the day of treatment and returned to their original pattern of sweating after 2 days. One patient (4\%) had continued anhidrosis up to 4 days after treatment.

There was a decrease in the mean of Hyperhidrosis Disease Severity Scale (HDSS) after the treatment with both modalities with percent of improvement $59.4 \%$. Similarly, Kim et al. ${ }^{(3)}$ showed that there was a decrease in HDSS score with the topical glycopyrrolate-treated half of the forehead, but the difference was not statistically significant $(\mathrm{P}>0.025)$.

All patients reported improvement of their dermatology life quality index (DLQI) after treatment. In the present study, most patients were satisfied with topical glycopyrrolate $2 \%$ and all patients expressed their desire to repeat the treatment. Also, Kim et al. ${ }^{(3)}$ showed that twenty patients were satisfied, four patients were partially satisfied because the amount of sweat reduction was lower than their expectations, and one patient was dissatisfied because of a transient headache that developed after the treatment by topical glycopyrrolate $2 \%$.

Regarding reported side effects, all treatmentrelated adverse events were temporary and did not prevent improvement of quality of life or make patients stop the treatment. Kim et al. ${ }^{(3)}$ reported that no serious adverse events were reported during the course of the study. Only one patient developed a transient headache after topical glycopyrrolate $2 \%$ treatment. Although topical application is often used to avoid systemic side-effects, it can result in contact sensitization, and the high concentration of drug needed for sufficient absorption through the skin can affect cholinergic nerve endings that may lead to systemic absorption and adverse effects ${ }^{(5)}$.

\section{CONCLUSION}

Topical Glycopyrrolate 2\% is safe, efficacious, well tolerated and convenient method in the treatment of facial hyperhidrosis with minimal, transient and well-tolerated side effects.

\section{ACKNOWLEDGEMENT}

The authors are grateful for the patients without whom this study would not have been done.

\section{REFERENCES}

1. Wolosker N, Krutman M, Teivelis M et al. (2014): Quality of life before hyperhidrosis treatment as a predictive factor for oxybutynin treatment outcomes in palmar and axillary hyperhidrosis. Ann Vasc Surg., 28 (4): 970-6.

2. Nicholas R, Quddus A, Baker D et al. (2015): Treatment of craniofacial hyperhidrosis: A systemic review. Am J Clin Dermatol., 16 (5): 361-370.

3. Kim W, Kil H, Yoon D et al. (2008): Topical glycopyrrolate for patients with facial hyperhidrosis. $\mathrm{Br}$ J Dermatol., 158 (5): 1094-1097.

4. Naumman M, Hofmann U, Burgmann I et al. (1998): Focal hyperhidrosis: Effective treatment with Botulinum toxin. Arch Dermatol., 134: 301-304 .

5. Hyun M, Son P, Lee $Y$ et al. (2015): Efficacy and safety of topical glycopyrrolate in patients with facial hyperhidrosis: a randomized, multicentre, double-blinded, placebo-controlled, split-face study. Journal of the European Academy of Dermatology and Venereology, 29 (2): 278-282.

6. Lowe N, Yamauchi P, Lask G et al. (2002): Efficacy and safety of botulinum toxin type a in the treatment of palmar hyperhidrosis: a double-blind, randomized, placebo-controlled study. Dermatol Surg., 28 (9): 8227.

7. Karlqvist M, Rosell K, Rystedt A et al. (2014): Botulinum toxin B in the treatment of craniofacial hyperhidrosis. J Eur Acad Dermatol Venereol., 28 (10): 1313-1317. 